\title{
In vitro Chemosensitivity of Head and Neck Cancer Cell Lines
}

\author{
P. J. Schuler ${ }^{1,5}$, S.Trellakis ${ }^{1}$, J. Greve ${ }^{1}$, M. Bas ${ }^{2}$, C. Bergmann ${ }^{1}$, E. Bölke ${ }^{3}$, G. Lehnerdt ${ }^{1}$, S. Mattheis ${ }^{1}$, \\ A. E. Albers ${ }^{4}$, S. Brandau ${ }^{1}$, S. Lang ${ }^{1}$, T. L. Whiteside ${ }^{5}$, H. Bier ${ }^{2}$, T. K. Hoffmann ${ }^{1}$ \\ ${ }^{1}$ Hals-Nasen-Ohrenklinik, Universität Duisburg-Essen, Essen, \\ ${ }^{2}$ Hals-Nasen-Ohrenklinik, Technische Universität München, Klinikum Rechts der Isar, München, \\ ${ }^{3}$ Klinik für Strahlentherapie und Radiologische Onkologie, Heinrich-Heine-Universität, Düsseldorf, \\ ${ }^{4}$ Hals-Nasen-Ohrenklinik, Charité - Universitätsmedizin Berlin, Campus Benjamin Franklin, Berlin, Germany, \\ ${ }^{5}$ Hillman Cancer Center, University of Pittsburgh, Pittsburgh, USA
}

\begin{abstract}
Background: Systemic treatment of head and neck squamous cell carcinoma (HNSCC) includes a variety of antineoplastic drugs. However, drug-resistance interferes with the effectiveness of chemotherapy. Preclinical testing models are needed in order to develop approaches to overcome chemoresistance.

Methods: Ten human cell lines were obtained from HNSCC, including one with experimentally-induced cisplatin resistance. Inhibition of cell growth by seven chemotherapeutic agents (cisplatin, carboplatin, 5- fluorouracil, methotrexate, bleomycin, vincristin, and paclitaxel) was measured using metabolic MT'T-uptake assay and correlated to clinically-achievable plasma concentrations.

Results: All drugs inhibited cell growth in a concentration-dependent manner with an IC50 comparable to that achievable in vivo. However, response curves for methotrexate were unsatisfactory and for paclitaxel, the solubilizer cremophor EL was toxic. Cross-resistance was observed between cisplatin and carboplatin. Conclusion: Chemosensitivity of HNSCC cell lines can be determined using the MTT-uptake assay. For DNAinterfering cytostatics and vinca alkaloids this is a simple and reproducible procedure. Determined in vitro chemosensitivity serves as a baseline for further experimental approaches aiming to modulate chemoresistance in HNSCC with potential clinical significance.
\end{abstract}

Key words: Head and neck cancer, Chemotherapy, Chemosensitivity, Cell line, MTT

\section{INTRODUCTION}

In addition to surgery and radiotherapy, antineoplastic chemotherapy is a standard treatment option for advanced head and neck squamous cell cancer (HNSCC) [1]. Chemotherapy is currently used in adjuvant or neoadjuvant settings combined with radiotherapy or, in a palliative situation, as a single modality. Agents used are the platinum based substances cisplatin (CIS) and carboplatin (CPT), 5-fluorouracil (5-FU) and taxanes alone or in combination [2]. But the efficacy of chemotherapy in HNSCC remains unsatisfactory due to the frequent development of non-responsiveness or chemoresistance [3]. Furthermore, the frequency of recurrent disease after chemotherapy has been unacceptably high [4]. In case of chemotherapeutically pretreated recurrent tumors, physicians are especially challenged to determine an appropriate therapy.

In order to overcome drug-resistance, the exploration of underlying mechanisms is necessary. To this end, in vitro models with cell lines established from human HNSCC have been used, and several chemotherapy sensitivity and resistance assays (CSRA) are currently available. These include: (a) the human tumor cloning assay; (b) the differential staining toxicity test, which identifies viable cells by differential dye staining; (c) the ATP-measurements after cell lysis; (d) the extreme drug-resistance assay, which measures the uptake of tritiated thymidine; or (e) the MT'T-assay based on the reduction of dimethyl thiazolyl blue (MTT) to purple formazan in viable cells. But, as stated by the American Society of Clinical Oncology (ASCO) in 2004, none of the available CSRA is suitable for routine clinical use, because these assays either lack an adequate prospective evaluation or they show no improvement towards empirically given treatment. Therefore, chemosensitivity testing is only recommended in a clinical trial setting [5].

The aim of this study was to evaluate the predictive capability of MTT-uptake tests towards chemosensitivity in HNSCC. For this purpose, ten HNSCC cell lines were tested for chemosensitivity against seven cytostatic drugs commonly used in the clinic, namely CIS, CPT, 5-FU, methotrexate (MTX), bleomycin (BLM), vincristine (VCR), and paclitaxel (PTX). All drugs were tested at the plasma concentrations achievable in vivo. The obtained results can, therefore, be easily adopted into clinical settings with potentially significant influence on patients' treatment.

\section{Materials AND METHODS}

Cell culture. For in vitro testing of chemosensitivity, ten established HNSCC cell lines were used. All UMSCC-lines (University of Michigan Squamous Cell Carcinomas) were kindly provided by Dr. T. Carey, University of Michigan, Ann Arbor, USA. Characterization and establishment of these cell lines were previously described [6]. Cell line HLac 79 was obtained 
Table 1. Description and origin of HNSCC cell lines including therapy received and survival of patients whose tumors were established in culture.

UM-SCC 10A Larynx carcinoma (T3), biopsy taken during surgical treatment, survival time 22 months

UM-SCC 10B Biopsy of metastasis in a cervical lymph node of the primary tumor UM-SCC 10A

UM-SCC 11B Larynx carcinoma (T2N2a) after chemotherapy with CIS and BLM. Biopsy taken during surgery, survival time 14 months

UM-SCC 14A Recurrent carcinoma of the mouth (T1N0) after repeated surgical treatment and radiotherapy. Biopsy taken during surgery, survival time 93 months

UM-SCC 14B Biopsy of second recurrence of carcinoma UM-SCC 14A before treatment

UM-SCC 14C Biopsy of third recurrence of carcinoma UM-SCC 14A after surgery and chemoradiotherapy with 5-FU, VCR and MTX

UM-SCC 22B Metastasis in a cervical lymph node of a previously untreated hypopharynx carcinoma (T2N1M0), survival time 10 months

HLac 79 Metastasis in a cervical lymph node of a larynx carcinoma

8029 NA Recloned subpopulation of HLac 79 (limiting dilution)

8029 DDP Variant of 8029 NA with experimentally induced CIS resistance

from H.P. Zenner, Tuebingen, Germany. The 8029 NA cell line and its CIS-resistant variant 8029 DDP were recloned from the cell line HLac 79 by Bier et al. [7]. The origin of each cell line is described in Table 1. All cell lines were cultured in Dulbecco's modified Eagle's medium (cDMEM, Sigma Chemical, St. Luis, USA) supplemented with $2 \mathrm{mM}$ L-gluthamine, $1 \%$ penicillin-streptomycin, 1\% non-essential amino acids (ICN, Eschwege, Germany), and 10\% fetal bovine serum, in a humidified atmosphere of $5 \% \mathrm{CO}_{2}$ at $37^{\circ} \mathrm{C}$. Mycoplasma detection tests were regularly performed. Viability and the number of tumor cells were assessed by the trypan blue dye exclusion test.

Drugs and cell treatment. Antineoplastic drugs were obtained as follows: CIS-platinex solution, CPT-carboplat-50 solution and paclitaxel-taxol solution (all Bristol, Munich, Germany), BLM lyophilised bleomycinsulfate (Mack, Illertissen, Germany), 5-FU-solution (Rhone-Poulenc, Cologne, Germany), methotrexate solution (Lederle, Wolfratshausen, Germany), VCR solution (Lilly, Giessen, Germany). After one week of incubation in culture plates, tumor cells were trypsinised into single cell suspensions. Aliquots $(200 \mu \mathrm{L})$ of each cell suspension were placed in wells of 96-well-plates (Falcon, Lincoln Park, New Jersey, USA). Preliminary tests were conducted with cell numbers between 3,000 and 25,000 per well. The optimal time periods between cell collection and drug administration as well as between the drug administration and M'T'T-testing were determined. Drug concentrations which resulted in $50 \%$ inhibition of cell growth were also determined in preliminary tests with various drug concentrations and are represented by the specific half maximal inhibitory drug concentration (IC50). Each cell line was treated with at least five different drug concentrations, to establish the IC50 of each cytostatic agent. Control wells received medium alone. In order to identify potential interference of the lipophilic solubilizer, cell lines UMSCC 11B, 14C, 22B and HLac 79 were exposed to paclitaxel (PTX) + cremophor EL (CEL) versus dimethyl sulfoxide (DMSO) as well as solubilizers alone.

MTT-assay. The MTT test is based on the reduction of yellow tetrazolium to purple formazan by the dehydrogenase in cells with metabolic activity compared to metabolically inactive cells treated with DMSO [8]. Tumor cells were incubated for $4 \mathrm{~h}$ with $50 \mu \mathrm{L}$ dimethylthiazole diphenyltetrazolium bromide per well (MTT 0.1\%, Sigma, Deisenhofen). Formazan was taken into solution with DMSO (Sigma, Munich, Germany) and absorption was determined at $540 \mathrm{~nm}$ using a photometer (Ear 400 ATX, SLT-labinstruments, Crailsheim, Germany). Wells with medium, cytostatic drug or DMSO alone served as negative controls.

Graphs and statistics. For each cell line, photometric results of five different drug concentrations were used for calculation of the IC50. In the plots, the y-axis represents cell growth, with cell growth of the untreated controls representing 100\%. Increasing logarithmic drug concentrations are shown on the x-axis. Standard deviations of each measurement are displayed by vertical bars. Results were analysed by a nonlinear parameter estimation procedure (SAS-Institute Inc., Carey, NC). Points were adjusted to sigmoid curves $(\mathrm{r}>0.95)$ [9]. IC50-data were calculated as proposed by Hafner et al. [10] and displayed in half logarithmic graphs (Figs. $1+2$ ). Only the results for metothrexate and partly for VCR in cell lines UM-SCC 14A-C showed a biphasic course and IC50-data were determined graphically.

\section{RESULTS}

In preliminary experiments using different tumor cell numbers and various time periods, we established that the dose of 6,000 tumor cells per well was the optimal number for testing chemosensitivity, and this cell number was subsequently used in all assays. The standard experimental protocol included tumor cell plating on day 0 , change of medium and drug administration on day 3 and MT'T testing on day 6.

All tested drugs inhibited cell growth of HNSCC cell lines in a dose-dependent manner. The IC50 values are shown in Table 2. The results were correlated to maximum plasma concentrations of each drug (MPC), derived from patients undergoing antineoplastic therapy as previously described [11-13]. According to the grade of chemosensitivity, cell lines were divided into three groups per cytostatic drug. The first group represents cell lines whose IC50 were notably under the MPC values. All cell lines with IC50 values close to the MPC values were included in the second group. The third group contains cell lines with IC50 values higher than MPC values. Dose response curves were created for each cell line. All graphs show a sigmoid curve, with the exception of UM-SCC 14A-C cell lines ex- 


\section{Cisplatin}
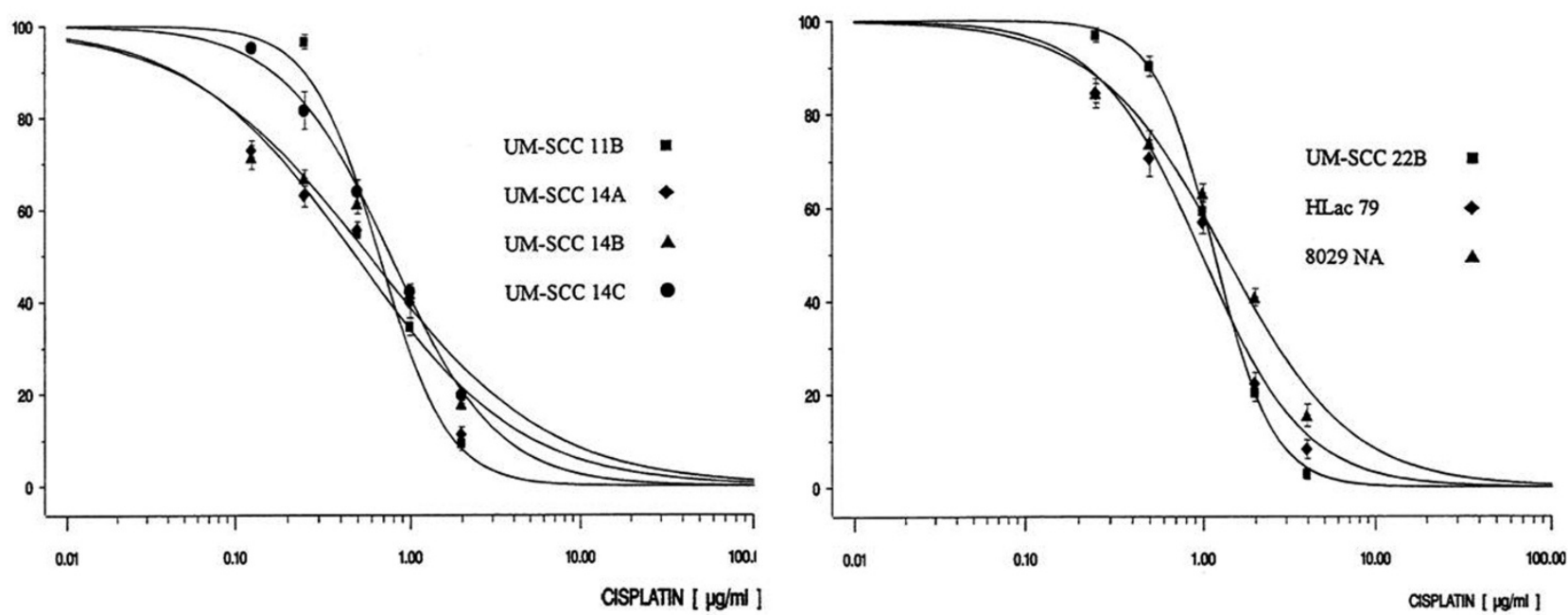

\section{Carboplatin}
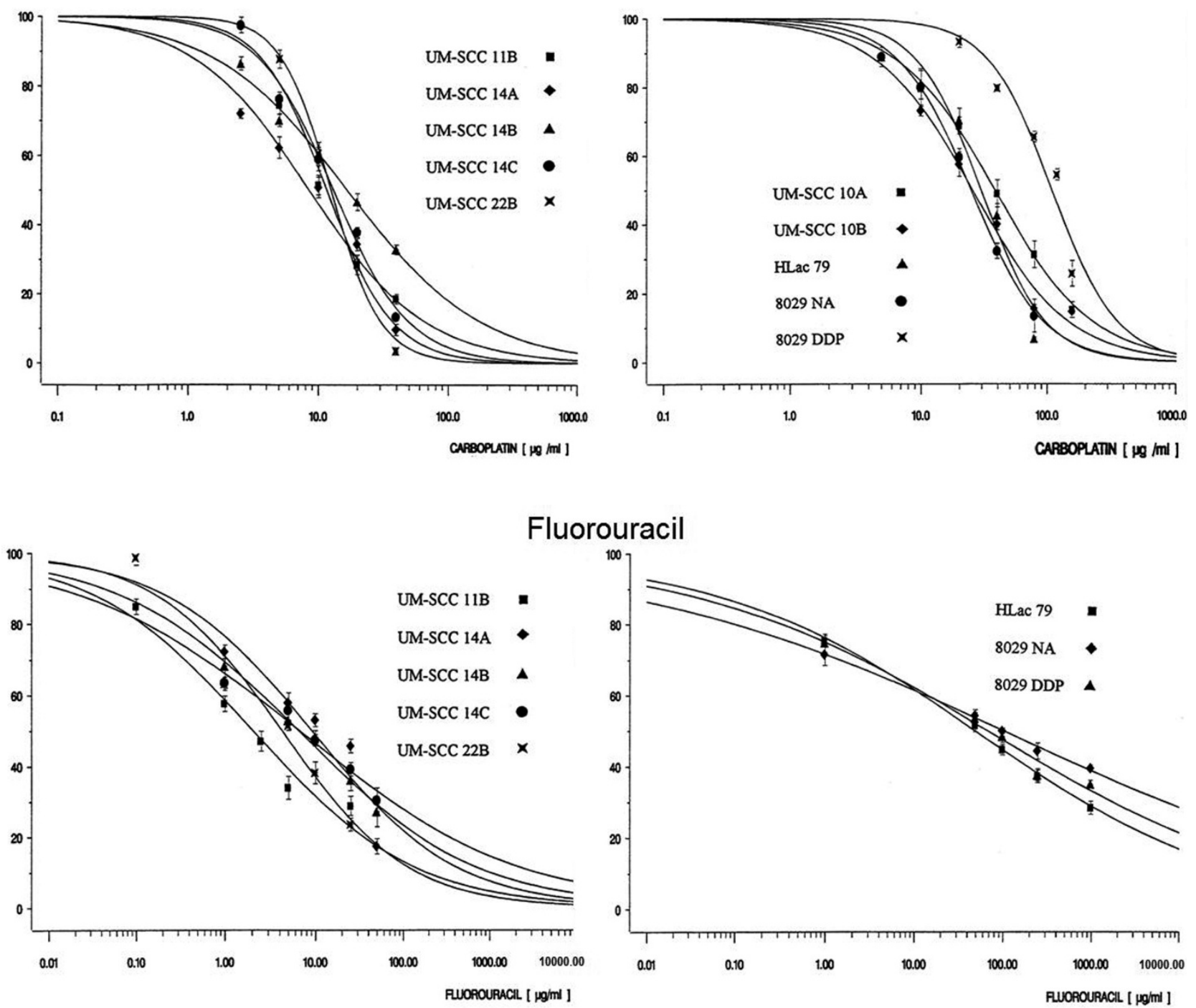

Fig. 1. Growth (y-axis) of HNSCC cell lines by increasing drug concentration (x-axis). A) Representative graphs for cell lines with low and medium IC50 compared to MPC values in humans for CIS. B) Cell lines with lower/medium and higher IC50 for CPT and C) cell lines with low and medium IC50 compared to MPC values in humans for 5-FU. 


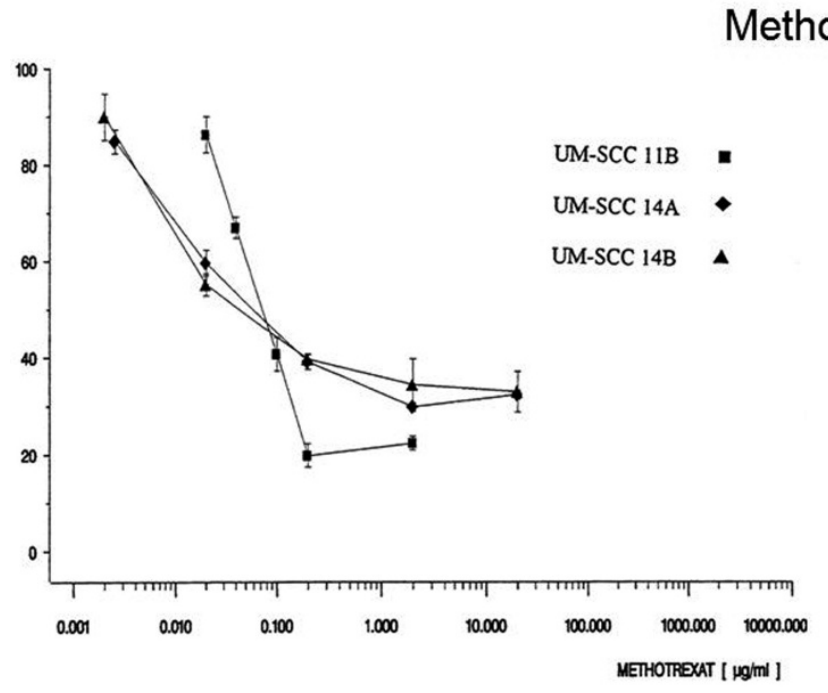

\section{Methotrexate}

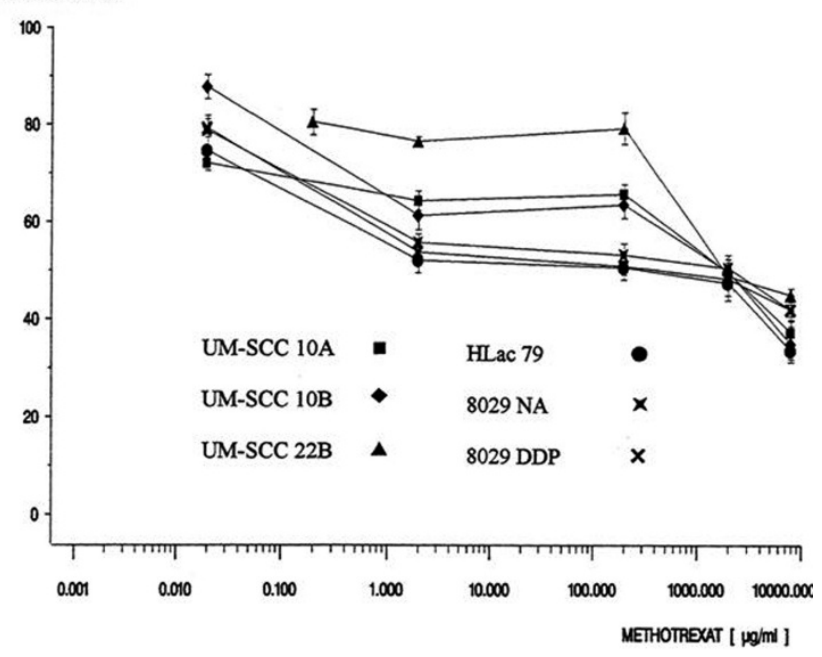

\section{Bleomycin}
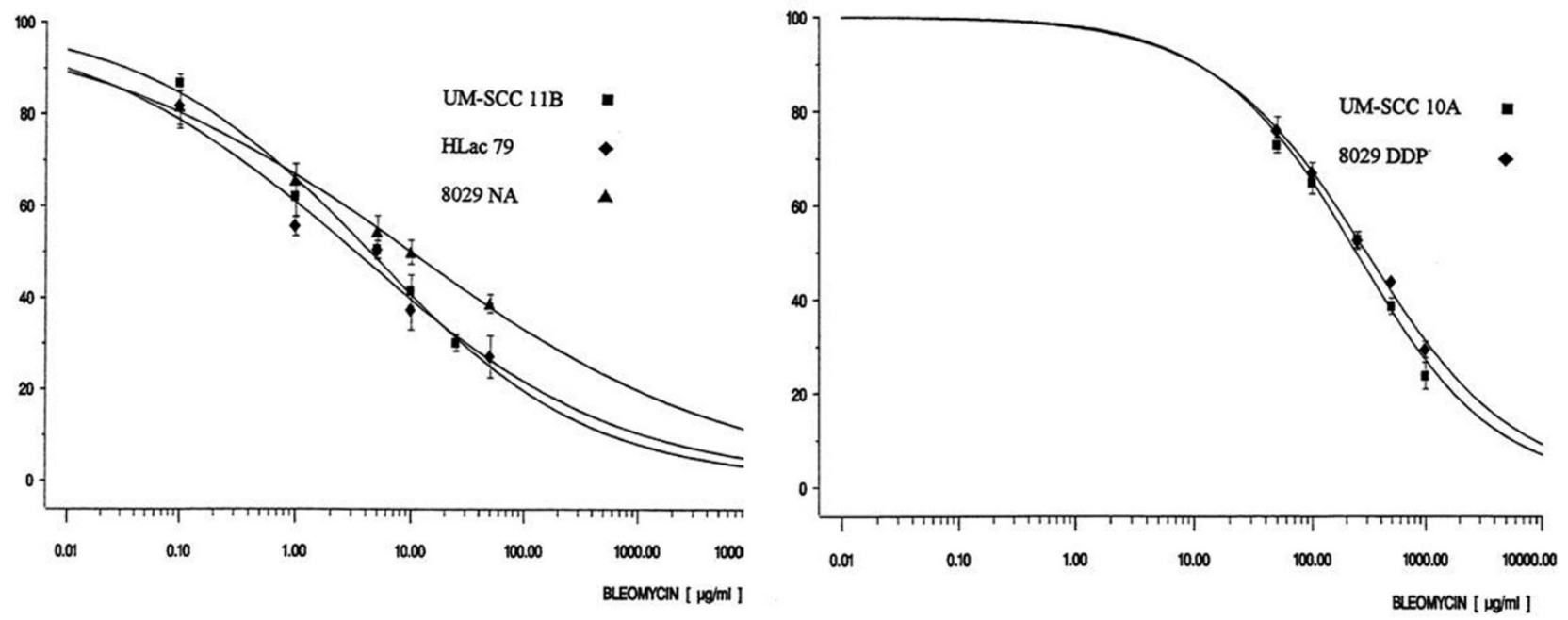

Fig. 2. Growth (y-axis) of HNSCC cell lines by increasing drug concentration (x-axis). A) Non-sigmoid course of cell lines with IC50 lower and higher than MPC values for MTX. B) Cell lines with lower and higher IC 50 than MPC values for BLM.
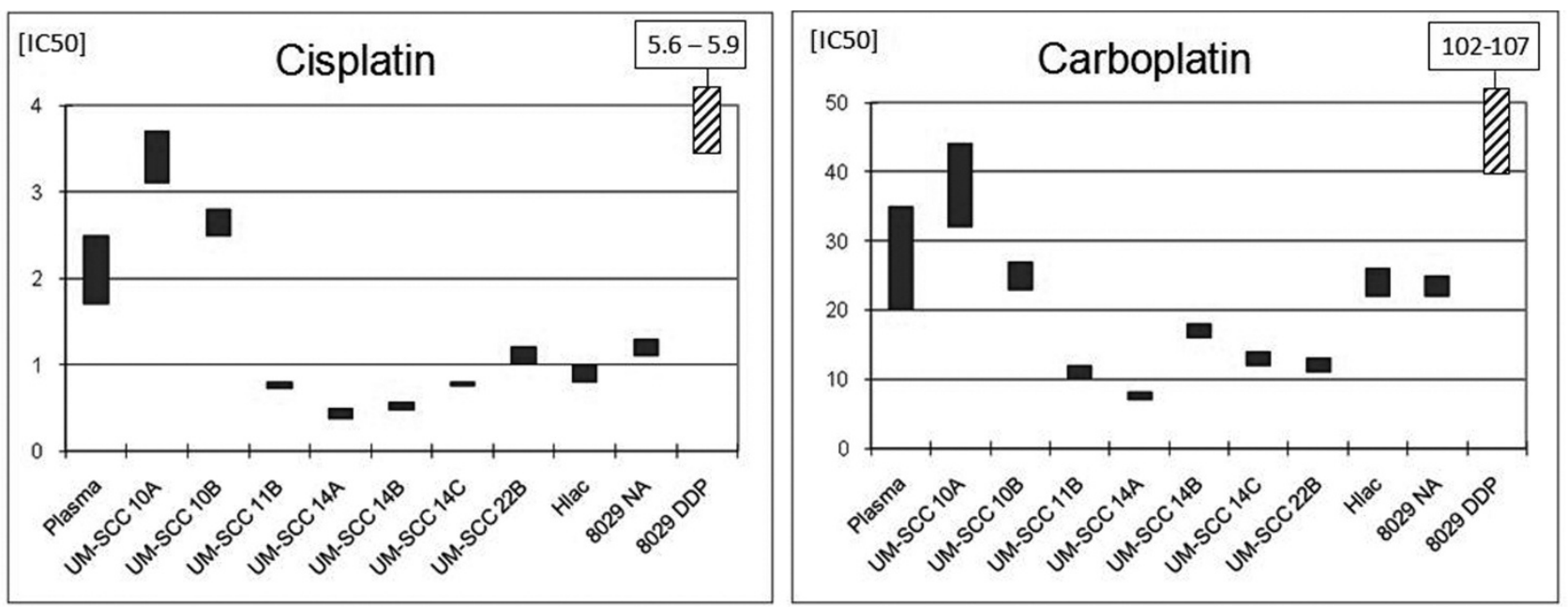

Fig. 3. IC50 values for CIS and CPT for each specific cell line. MPC values are displayed in the first column (plasma). MCP value for CIS is $1.7-2.5 \mu \mathrm{g} / \mathrm{mL}$ (left panel) and MCP value for CPT is $20-35 \mu \mathrm{g} / \mathrm{mL}$ (right panel). Cross-resistance between CIS and CPT is displayed by increased IC50 values for both agents in cell lines UM-SCC 10A and 8029 DDP. 


\begin{tabular}{|c|c|c|c|c|c|c|}
\hline Cell line & Cisplatin & Carboplatin & 5-FU & MTX & Bleomycin & Vincristine \\
\hline UM-SCC 10A & $\begin{array}{c}3.4 \\
(3.1-3.7) \\
\end{array}$ & $\begin{array}{c}37 \\
(32-44) \\
\end{array}$ & $\begin{array}{c}4,677 \\
(2,238-9,772) \\
\end{array}$ & 2,000 & $\begin{array}{c}234 \\
(214-257) \\
\end{array}$ & $\begin{array}{c}0.009 \\
(0.007-0.011)\end{array}$ \\
\hline UM-SCC 10B & $\begin{array}{c}2.6 \\
(2.5-2.8)\end{array}$ & $\begin{array}{c}25 \\
(23-27)\end{array}$ & $\begin{array}{c}490 \\
(331-724)\end{array}$ & 2,000 & $\begin{array}{c}21 \\
(20-23)\end{array}$ & $\begin{array}{c}0.01 \\
(0.009-0.013)\end{array}$ \\
\hline UM-SCC 11B & $\begin{array}{c}0.76 \\
(0.72-0.79)\end{array}$ & $\begin{array}{c}11 \\
(10-12)\end{array}$ & $\begin{array}{c}2.3 \\
(1.9-2.8)\end{array}$ & 0.04 & $\begin{array}{c}4.4 \\
(4.2-4.6)\end{array}$ & $\begin{array}{c}0.002 \\
(0.002-0.002)\end{array}$ \\
\hline UM-SCC 14A & $\begin{array}{c}0.44 \\
(0.38-0.49)\end{array}$ & $\begin{array}{c}7.6 \\
(7.1-8.1)\end{array}$ & $\begin{array}{c}7.9 \\
(6.9-9.1)\end{array}$ & 0.06 & $\begin{array}{c}38 \\
(31-47)\end{array}$ & 55 \\
\hline UM-SCC 14B & $\begin{array}{c}0.52 \\
(0.48-0.57) \\
\end{array}$ & $\begin{array}{c}17 \\
(16-18) \\
\end{array}$ & $\begin{array}{c}6.5 \\
(4.9-8.5) \\
\end{array}$ & 0.07 & $\begin{array}{c}24 \\
(20-29)\end{array}$ & 47 \\
\hline UM-SCC 14C & $\begin{array}{c}0.78 \\
(0.76-0.79)\end{array}$ & $\begin{array}{c}13 \\
(12-14)\end{array}$ & $\begin{array}{c}6.3 \\
(5.8-6.9)\end{array}$ & 6 & $\begin{array}{c}30 \\
(28-32)\end{array}$ & 80 \\
\hline UM-SCC 22B & $\begin{array}{c}1.1 \\
(1.0-1.2) \\
\end{array}$ & $\begin{array}{c}12 \\
(11-13)\end{array}$ & $\begin{array}{c}4.5 \\
(4.0-5.0) \\
\end{array}$ & 2,000 & $\begin{array}{c}13 \\
(11-15) \\
\end{array}$ & $\begin{array}{c}0.009 \\
(0.008-0.009)\end{array}$ \\
\hline Hlac 79 & $\begin{array}{c}0.9 \\
(0.8-1.0)\end{array}$ & $\begin{array}{c}24 \\
(22-26)\end{array}$ & $\begin{array}{c}48 \\
(41-56)\end{array}$ & 230 & $\begin{array}{c}3.4 \\
(2.2-5.2)\end{array}$ & $\begin{array}{c}0.003 \\
(0.002-0.003)\end{array}$ \\
\hline 8029 NA & $\begin{array}{c}1.2 \\
(1.1-1.3)\end{array}$ & $\begin{array}{c}23 \\
(22-25)\end{array}$ & $\begin{array}{c}105 \\
(98-112)\end{array}$ & 330 & $\begin{array}{c}9.5 \\
(7.8-12)\end{array}$ & $\begin{array}{c}0.003 \\
(0.003-0.004)\end{array}$ \\
\hline $\begin{array}{c}8029 \text { DDP } \\
\text { cisplatin resistant }\end{array}$ & $\begin{array}{r}5.8 \\
(5.6-5.9) \\
\end{array}$ & $\begin{array}{c}105 \\
(102-107) \\
\end{array}$ & $\begin{array}{c}69 \\
(63-76) \\
\end{array}$ & 1,800 & $\begin{array}{c}288 \\
(275-302) \\
\end{array}$ & $\begin{array}{c}0.008 \\
(0.007-0.009) \\
\end{array}$ \\
\hline & & & & & & \\
\hline $\begin{array}{c}\text { IC50-Range } \\
\text { [ } \mu \mathrm{g} / \mathrm{ml}]\end{array}$ & $0.44-5.8$ & $7.6-105$ & $2.3-4,677$ & $0.04-2,000$ & $3.4-288$ & $0.002-80$ \\
\hline $\begin{array}{l}\text { Variation } \\
\text { [x-times] }\end{array}$ & 13 & 14 & 2,030 & 50,000 & 85 & 40,000 \\
\hline $\begin{array}{l}\text { Standard dose } \\
\text { i.v. in Patient }\end{array}$ & $100 \mathrm{mg} / \mathrm{m}^{2}$ & $400 \mathrm{mg} / \mathrm{m}^{2}$ & $15 \mathrm{mg} / \mathrm{kg}$ & $30 \mathrm{mg} / \mathrm{m}^{2}$ & $15 \mathrm{U} / \mathrm{m}^{2}$ & $0.025 \mathrm{mg} / \mathrm{kg}$ \\
\hline $\begin{array}{l}\text { Max. Plasma } \\
\text { Conc. [ } \mu \mathrm{g} / \mathrm{ml}]\end{array}$ & $1.7-2.5$ & $20-35$ & $60-200$ & $2-4$ & $10-40$ & $0.37-1$ \\
\hline
\end{tabular}

Table 2. Drug concentrations which lead to a $50 \%$ inhibition of cell growth (IC50) were determined for each cell line using six common antineoplastic agents. Standard errors (SE) on a logarithmic scale are given in parentheses. Data for MTX, and partly for VCR, were determined in the corresponding graph due to their non-sigmoid curves. No SE were calculated for MTX and partly for VCR because of the linear response curves. The range of IC50 values is displayed for each cytostatic drug. The quotient of the highest and lowest IC50 value is displayed in the variation row. Maximum plasma concentrations (MPC) are based on in vivo measurements performed as described.

IC50 values \begin{tabular}{|l|l|l|}
\hline lower & in range & higher \\
\cline { 2 - 4 } than MPC values
\end{tabular}

posed to VCR, all methotrexate measurements (Fig. 2A) and UM-SCC 10A-B cell lines exposed to 5-FU. Their linear graphs lead to high variation factors for VCR (40,000), MTX (50,000) and 5-FU (2,030). For each drug, two representative graphs are shown in Figure 1 and 2, except for PTX and VCR.

For CIS and CPT, the IC50 values were compared to MPC values and are separately displayed in Figure 3. Cell lines UM-SCC 10A and B derive from a patient with previously untreated larynx carcinoma. Their IC50 values for CIS lie above the MPC values and are indicative of a primary resistance to platinum-derived drugs. In the cell line 8029 DDP, CIS resistance was experimentally induced in its precursor cell line 8029 NA by a gradual increase of in vitro CIS concentrations [7]. Here, the IC50 value for CIS was 2.8-fold higher than the MPC value and 4.8-fold higher than IC50 in the parental cell line 8029 NA. At the same time, a cross-resistance to CPT was induced, as indicated by the IC50 value for CPT $(5.8 \mu \mathrm{g} / \mathrm{mL})$ which was 3.9-fold higher than the MPC value (1.7-2.5 $\mu \mathrm{g} / \mathrm{mL}$ ) and 4.6-fold higher than the IC50 value for cell line 8029 NA $(1.2 \mu \mathrm{g} / \mathrm{mL})$. Furthermore, cross-resistance against BLM and methotrexate was observed: after experimental induction of CIS resistance in cell line 8029 DDP, the IC50 value was 30-fold higher for BLM and 5.5-fold higher for MTX compared to the parental cell line 8029 NA (Table 2). All other cell lines displayed IC50 values under or in range of the respective MPC values for CIS and CPT.

For VCR, the IC50 values for cell lines UM-SCC $14 \mathrm{~A}-\mathrm{C}$ were 5,000 -fold higher $(47-80 \mu \mathrm{g} / \mathrm{mL})$ than in other cell lines and 50-fold higher than MPC (0.37-1 $\mu \mathrm{g} / \mathrm{mL})$. Additionally, during therapy, VCR resistance increased from $47 \mu \mathrm{g} / \mathrm{mL}$ in UM-SCC $14 \mathrm{~B}$ to 80 $\mu \mathrm{g} / \mathrm{mL}$ in UM-SCC 14C. Several other cell lines showed a secondary increase of cell growth in terms of a biphasic course under the influence of high VCR concentrations (data not shown). Possibly, high levels of VCR might induce an elongation of the cell cycle arrest, but so far, the nature of this systematic interfering factor remains unknown.

Cell lines UM-SCC 11B, 14C, 22B and HLac 79 were additionally exposed to PTX combined with CEL or DMSO. For both combinations a strong dose response was observed which correlated with the drug concentrations ranging between 0.002 and 0.02 $\mu \mathrm{g} / \mathrm{mL}$. But PTX proved to be ten-fold more effective in combination with CEL compared to DMSO. Moreover, for CEL, the drug concentration for the typical drop-off in the dose response curve was only 100 -fold higher compared to PTX + CEL. For DMSO the drop-off concentration was 10,000-fold higher than for PTX + DMSO. This shows that in all tested cell lines (UM-SCC 11B, 14C, 22B, and HLac 79) CEL induced an additional cytotoxity in concentrations above human IC50 levels. Therefore, the specific cytotoxic activity of CEL in vitro should be considered in future drug-resistance experiments with PTX. The present studies were continued without PTX, as its solubilizers CEL and DMSO had an unpredictable influence on chemosensitivity in vitro.

The chemotherapeutically pre-treated cell line UMSCC $11 \mathrm{~B}$ was extremely sensitive to all tested cytostatic agents and showed no drug-resistance. These findings are in accordance with previous data for this cell line, but they do not correlate with clinical experience, as HNSCC frequently develop secondary resistance to 
chemotherapy [14]. In this case, insufficient drug concentrations must be considered because no drug resistance was determined and the survival time of 14 months was rather short.

\section{Discussion}

For DNA-interfering cytostatics and vinca alkaloids (VCR), the MTT-assay is a simple and reproducible procedure for determining chemosensitivity in $\mathrm{HN}$ SCC. It has the potential to be predictive of in vivo responses in patients undergoing chemotherapy, and the potential value was tested in this study. The predictive capability of the MT'T-assay was evaluated using allogeneic tumor cell lines which were exposed to the cytotoxic drugs used at concentrations adjusted to those usually achieved in vivo (MPC) in HNSCC patients [11-13]. Also, the origin of the cell lines, the type of therapy the donating patients had undergone and, in most cases, the survival time after chemotherapy were known. This information was valuable for the interpretation of in vitro responses of tumor cells to the drugs in the context of the tumor type and the patient clinical history. Even with only ten allogeneic HNSCC cell lines, it was clear that their chemosensitivities to six drugs were quite different, providing an indication as to a potential in vivo response of the tumor to the MPC dose of each drug. Therefore, results of the MTT-assays were informative with allogeneic cell lines used as targets. It can be surmised that the use of autologous cell lines although demanding, would be even more informative. Indeed, currently available methods allow for short-term culture of patient-specific tumor cultures that are then tested in chemosensitivity assays in order to help in selection of the optimal drug and to predict a favorable response [15]. Results of such chemosensitivity screens and their predictive accuracy appear to be reasonable, although their clinical use has not been broadly accepted so far, and efforts to establish the role of chemosensitivity testing in predicting longer patient survival are ongoing [16].

In this study, tumor cell growth conditions in culture and concentrations of drugs used were established to approximate those present in vivo. However, comparable to most other in vitro experiments, the MTT-assay was performed in a fibroblast-free culture to avoid interference by outgrowing fibroblasts [17]. It is necessary to remember that the tumor microenvironment, including various cellular components of tumor stroma, is likely to substantially influence tumor behavior in vitro and in vivo [18]. Also, culturing tumor cells as monolayers does not reproduce the true in vivo situation. Multilayer or spheroid models and the histoculture drug response assays (HDRA) are three-dimensional tumor models which regularly measure higher resistance levels against cytostatic drugs than the monolayer models [19]. The predictive capability of the MT'T-assay would probably increase, if it could be implemented in such multi-dimensional models, especially those established using autologous tumor cells. On the other hand, this strategy is likely to also contribute to the assay complexity and its cost. Our results and those of others suggest that in vitro testing of chemosensitivity using cultured tumor cells has a clinical utility. Additionally, the emergence of new anti-neoplastic agents in oncology calls for further development of assays which are able to reliably predict tumor chemoresistance. For these reasons, the application of MTT-based assays to clinical decision making and their improved predictive significance in estimates of chemosensitivity are becoming an important component of oncologic practice.

Among the cytostatics with widespread use in cancer treatment are platinum-based agents, CIS and CPT, and resistance of tumor cells to these drugs is of great interest. The best known mechanisms of platinum-based drug resistance include: (a) up-regulation of copper efflux transporters in the tumor cell membrane [20]; (b) reduced absorption of CIS; (c) up-regulated intracellular DNA repair systems [21]; and (d) increased intracellular gluthatione [22]. Furthermore, the influence of p53 mutations on CIS sensitivity has been suggested [23], and distinct changes in gene expression, e.g. c-met, have been described in CIS resistant tumor cell lines [24]. These resistance mechanisms may apply to the cell line 8029 DDP used in our experiments. Cross-resistance to BLM was observed in this CIS-resistant cell line, which displayed an increased IC50 value for BLM after experimental induction of CIS resistance. So far, no connection between BLM and CIS resistance has been described, but the phenomenon of multidrug-resistance based on the involvement of multiple membranous transport proteins could be a relevant mechanism [14]. When comparing the chemosensitivity results for the two platinum-based agents (CIS and CPT) in HNSCC cell lines, similar antineoplastic activity was observed suggesting that the cause of cross-resistance lies in the structural and functional analogy of the platinbased cytostatics. However, to obtain an equivalent antineoplastic activity, a 16-fold higher concentration of CPT than CIS was necessary, as also reported by others [25]. The relatively low activity of CPT is believed to depend on its decreased ability to form intrastrand crosslinks [26]. The issue of CIS resistance is of especially high clinical interest in head and neck oncology and may be approached systematically by using the current in vitro model. The present work offers a baseline for further identification of drug-resistance mechanisms in HNSCC by providing detailed chemosensitivity data obtained in several tumor cell lines.

Due to its high response rate combined with low toxicity, MTX is a favourable cytostatic drug in palliative treatment of HNSCC. However, our data show poor response level for MTX with several cell lines displaying an IC50 value which was only just below or above MPC values. After tumor biopsy to establish the cell line UM-SCC 14B, the patient was treated with surgery as well as MTX, 5-FU and VCR in a multi-drug regimen. UM-SCC 14C was taken from recurrent disease, which presumably acquired an increased resistance against these drugs. In our panel of cell lines, MTX resistance was 100-fold higher in UM-SCC 14C compared to the precursor cell lines UM-SCC 14A and B. So, despite the poor response levels for MTX, secondary drug resistance was recognized correctly by MTT-uptake. However, 
the plateau in the graph for MTX resistance might have resulted in significant but not necessarily biologically important statistical differences in the IC50 values.

In the same cell lines, UM-SCC $14 \mathrm{~A}-\mathrm{C}$, it was shown that the tumor possessed a primary resistance to VCR, as IC50 levels of these tumor samples were manifold increased. Still, VCR resistance increased during therapy. Therefore, it is reasonable that treatment with VCR in this patient had the same effect as low-dose chemotherapy which leads to an increase of drug resistance. Similar conditions can develop in nonresistant tumors in vivo, where various factors like superinfection, variation of blood supply and heterogeneity of the tumor (e.g. central necrosis, fibrosis) lead to inconsistent drug concentrations in situ. In this way, solid tumors create ideal conditions for the development of drug-resistance by low cytostatic drug concentrations [27].

Also in the same cell lines, UM-SCC 14B and C, no change was seen in 5-FU resistance, despite the fact, that the multidrug treatment included 5-FU. This could be due to an insufficient drug concentration or the lack of predictive capability in the experimental setting for 5-FU. Summarizing the results for cell lines UM-SCC 14A-C, the MTT-assay correctly recapitulated results for MTX and VCR, but those for 5-FU remain questionable. The non-sigmoid response curve for 5-FU in some of the cell lines (UM-SCC 10A and B), which lead to an increased variation factor, might be of experimental origin. Coley et al observed a cell swelling caused by an increase of intracellular mitochondria and consequently a simulation of higher absorbance levels under 5-FU in the MTT assays [28]. The same phenomenon was described using genistein, an unspecific tyrosine kinase inhibitor [29]. Therefore, obtained results for 5-FU must be viewed carefully, even though in other studies no interference with 5FU was described.

Acknowledgement: The authors wish to thank Tom Carey, who contributed the UM-SCC cell lines and provided us with valuable patient data.

\section{REFERENCES}

1. Oddone N, Morgan GJ, Palme CE et al. Metastatic cutaneous squamous cell carcinoma of the head and neck: the immunosuppression, treatment, extranodal spread, and margin status (ITEM) prognostic score to predict outcome and the need to improve survival. Cancer 2009;9: 1883-1891.

2. Ahmed SM, Cohen EE. Treatment of squamous cell carcinoma of the head and neck in the metastatic and refractory settings: advances in chemotherapy and the emergence of small molecule epidermal growth factor receptor kinase inhibitors. Curr Cancer Drug Targets 2007;7:666673.

3. Dollner R, Granzow C, Neudert M, Dietz A. Ex vivo chemosensitivity of head and neck carcinoma to cytostatic drug combinations. Anticancer Res 2006;2B:16511655.

4. Pignon JP, Bourhis J, Domenge C, Designe L. Chemotherapy added to locoregional treatment for head and neck squamous-cell carcinoma: three meta-analyses of updated individual data. MACH-NC Collaborative Group.
Meta-Analysis of Chemotherapy on Head and Neck Cancer. Lancet 2000;9208:949-955.

5. Schrag D, Garewal HS, Burstein HJ, Samson DJ, von Hoff DD, Somerfield MR. American Society of Clinical Oncology Technology Assessment: chemotherapy sensitivity and resistance assays. J Clin Oncol 2004;17:3631-3638.

6. Krause CJ, Carey TE, Ott RW, Hurbis C, McClatchey $\mathrm{KD}$, Regezi JA. Human squamous cell carcinoma. Establishment and characterization of new permanent cell lines. Arch Otolaryngol 1981;11:703-710.

7. Bier H, Bergler W, Mickisch G, Wesch H, Ganzer U. Establishment and characterization of cisplatin-resistant sublines of the human squamous carcinoma cell line HLac 79. Acta Otolaryngol 1990;5-6:466-473.

8. Carmichael J, DeGraff WG, Gazdar AF, Minna JD, Mitchell JB. Evaluation of a tetrazolium-based semiautomated colorimetric assay: assessment of chemosensitivity testing. Cancer Res 1987;4:936-942.

9. Poch G, Vychodil-Kahr S, Petru E. Sigmoid model versus median-effect analysis for obtaining dose-response curves for in vitro chemosensitivity testing. Int J Clin Pharmacol Ther 1999;4:189-192.

10. Hafner D, Heinen E, Noack E. Mathematical analysis of concentration-response relationships. Method for the evaluation of the ED50 and the number of binding sites per receptor molecule using the logit transformation. Arzneimittelforschung 1977;10:1871-1873.

11. Scheithauer W, Clark GM, Salmon SE, Dorda W, Shoemaker RH, Von Hoff DD. Model for estimation of clinically achievable plasma concentrations for investigational anticancer drugs in man. Cancer Treat Rep 1986;12:13791382.

12. van den Bongard HJ, Mathot RA, Beijnen JH, Schellens JH. Pharmacokinetically guided administration of chemotherapeutic agents. Clin Pharmacokinet 2000;5:345-367.

13. Rousseau A, Marquet P, Debord J, Sabot C, Lachatre G. Adaptive control methods for the dose individualisation of anticancer agents. Clin Pharmacokinet 2000;4:315-353.

14. Perez-Tomas R. Multidrug resistance: retrospect and prospects in anti-cancer drug treatment. Curr Med Chem 2006;16:1859-1876.

15. Brower SL, Fensterer JE, Bush JE. The ChemoFx assay: an ex vivo chemosensitivity and resistance assay for predicting patient response to cancer chemotherapy. Methods Mol Biol 2008;57-78.

16. Cree IA, Kurbacher CM, Lamont A, Hindley AC, Love S. A prospective randomized controlled trial of tumour chemosensitivity assay directed chemotherapy versus physician's choice in patients with recurrent platinum-resistant ovarian cancer. Anticancer Drugs 2007;9:10931101.

17. Abe R, Ueo H, Akiyoshi T. Evaluation of MTT assay in agarose for chemosensitivity testing of human cancers: comparison with MTT assay. Oncology 1994;5:416425.

18. Strauss L, Bergmann C, Szczepanski M, Gooding W, Johnson JT, Whiteside TL. A unique subset of CD4+CD25highFoxp3+ $\mathrm{T}$ cells secreting interleukin-10 and transforming growth factor-beta1 mediates suppression in the tumor microenvironment. Clin Cancer Res 2007;15 Pt 1:4345-4354.

19. Padron JM, van der Wilt CL, Smid K et al. The multilayered postconfluent cell culture as a model for drug screening. Crit Rev Oncol Hematol 2000;2-3:141-157.

20. Kuo MT, Chen HH, Song IS, Savaraj N, Ishikawa T. The roles of copper transporters in cisplatin resistance. Cancer Metastasis Rev 2007;1:71-83.

21. Borst P, Rottenberg S, Jonkers J. How do real tumors become resistant to cisplatin? Cell Cycle 2008;10:1353-1359.

22. Cullen KJ, Newkirk KA, Schumaker LM, Aldosari N, Rone JD, Haddad BR. Glutathione S-transferase pi ampli- 
fication is associated with cisplatin resistance in head and neck squamous cell carcinoma cell lines and primary tumors. Cancer Res 2003;23:8097-8102.

23. Hoffmann TK, Sonkoly E, Hauser U et al. Alterations in the p53 pathway and their association with radio- and chemosensitivity in head and neck squamous cell carcinoma. Oral Oncol 2008;12:1100-1109.

24. Akervall J, Guo X, Qian CN et al. Genetic and expression profiles of squamous cell carcinoma of the head and neck correlate with cisplatin sensitivity and resistance in cell lines and patients. Clin Cancer Res 2004;24:8204-8213.

25. Hasegawa Y, Goto M, Hanai N et al. Evaluation of optimal drug concentration in histoculture drug response assay in association with clinical efficacy for head and neck cancer. Oral Oncol 2007;8:749-756.

26. Knox RJ, Friedlos F, Lydall DA, Roberts JJ. Mechanism of cytotoxicity of anticancer platinum drugs: evidence that cis-diamminedichloroplatinum(II) and cis-diammine(1,1-cyclobutanedicarboxylato)platinum(II) differ only in the kinetics of their interaction with DNA. Cancer Res 1986;4 Pt 2:1972-1979.

27. Bier H. Chemotherapeutic drug resistance in the management of head and neck cancer. Eur Arch Otorhinolaryngol 1993;4:200-208.

28. Coley HM, Lewandowicz G, Sargent JM, Verrill MW. Chemosensitivity testing of fresh and continuous tumor cell cultures using lactate dehydrogenase. Anticancer Res 1997;1A:231-236.

29. Pagliacci MC, Spinozzi F, Migliorati G et al. Genistein inhibits tumour cell growth in vitro but enhances mitochondrial reduction of tetrazolium salts: a further pitfall in the use of the MTT assay for evaluating cell growth and survival. Eur J Cancer 1993;11:1573-1577.

Received: May 14, 2010 / Accepted: June 17, 2010

Address for correspondence:

Dr. med. Patrick Schuler

Hals-Nasen-Ohrenklinik

Universität Duisburg-Essen

Hufelandstr. 55

45147 Essen

Germany

Office: +49-201-723-2481

Fax: +49-201-723-5903

Email: patrick.schuler@uk-essen.de 